\section{Recency Effect}

Angela K. Troyer

Neuropsychology and Cognitive Health Program, Baycrest Centre for Geriatric Care, Toronto, ON, Canada

\section{Definition}

The recency effect is the tendency for individuals without neurological impairment to show enhanced memory for items presented at the end of a list relative to items presented in the middle of the list. Immediately after presentation, items presented at the end of a list can be retrieved from short-term or primary memory. The recency effect, therefore, is characterized by features of short-term memory ability such as susceptibility to interference and rapid decay. The recency effect is part of the larger serial position effect.

\section{Cross-References}

- Primacy Effect

- Serial Position Effects

\section{References and Readings}

Tulving, E., \& Craik, F. I. M. (Eds.). (2000). The Oxford handbook of memory. New York: Oxford University Press. 